\title{
AUDIT SISTEM INFORMASI
}

SMK FARMASI CENDIKIA FARMA HUSADA

(DEVISI BENDAHARA)

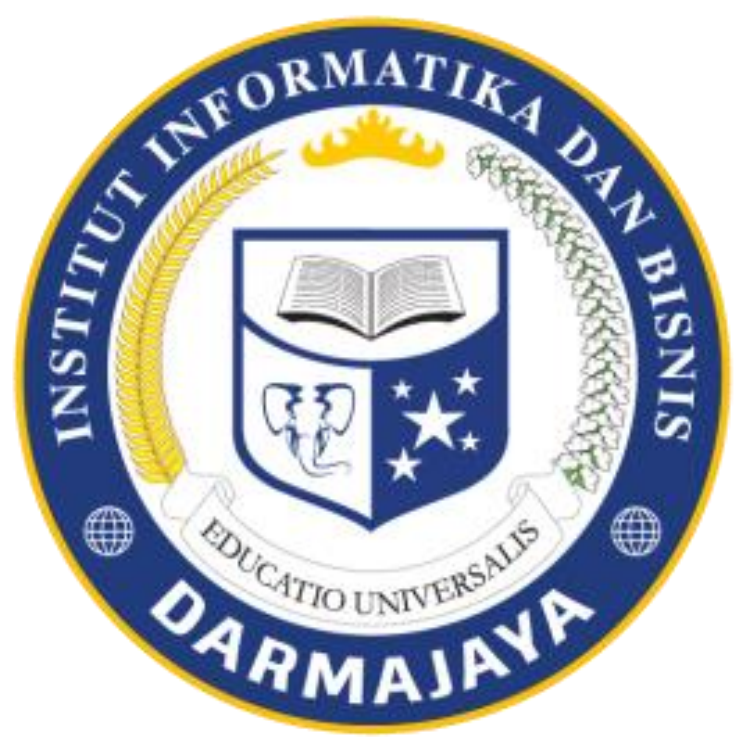

NAMA : IRMAWATY SIMANJUNTAK

NPM $\quad: 1611050193$

JURUSAN SISTEM INFORMASI

INSTITUT INFORMATIKA DAN BISNIS DARMAJAYA 


\section{BAB I}

\section{SEJARAH SMK FARMASI CENDIKIA FARMA HUSADA}

Sekolah menengah kejuruan (SMK) farmasi cendikia farma husada dirintis sejak mei 2010 oleh praktisi apotikermuda yang berfossional dan kompeten dibidang kefarmasian yaitu Bpk.Hi ardyansyah khauripan, M,Si., Apt dibawah naungan yayasan cendikia farma husada.

SMK farmasi candika husada ini merupakan smk farmasi yang pertama berada diBandar Lampung yang kemuduan menjadi pelopor perkembangan smk farmasi diprovinsi Lampung. Sebagai sekolah farmasi plopor, SMK farmasi cendika terus melakukan pengebangan sistem kependiddikan farmasi sehinga tampil menjadi SMK farmasi favorit dan unggul.

Secara geografis gedung SMK farmasi cendikia farma husada terletak dilingkingan pemungkiman penduduk dikota Bandar Lampung tempatnya dijalan pulau enggano No.99, Kelurahan Sukabumi, Kecamatan Sukabumi, kota Bandar Lampung. Sekolah ini berdiri diatas tanah seluas $\pm 1.878 \mathrm{~m}^{2}$.

Secara topografi wilayah SMK farmasi cendikia farma husada merupakan daerah dataran yang subur dengan sumber air yang baik. Akses menuju sekolah dapat ditempuh dengan roda empat maupun roda dua.

Tata ruang gedung SMK farmasi candikia farma husada dibangun dengan konsep modren dan humanis sehingga interaksi guru dan siswa dalam proses pendidikan dapat terbangun dan terpelihara dengan baik. SMK farmasi candikia farma husada menyajikan fasilitas belajar yang nyaman dan memadai yaitu:

1. Gedung sekolah yang fresh dengan status milik sendiri (yayasan cendikia farma husada).

2. Laborarorium praktikum farmasetika yang lengkap dan ber-AC.

3. Ruang kelas multimedia (audio-visual/lcd proyektor) dan ber-AC.

4. Wifi/host spot area.

5. Perpustakaan

6. Kantin yang bersih dan nyaman

7. Mushola

8. Ruang perawatan kesehatan

9. Ruang sekretariat bersama unit kegiatan siswa

10. Lapangan bulu tangkis dan sepak takraw

11. Area parkir dan taman

12. Apotek pendidikan

13. Kebun tanaman obat

14. Fasilitas sanitasi yang baik. 
Letak sekolah yang tidak terlalu dekat dengan jalan raya menjadi nilai positif secara ekologis, sekolah tiadak bisik dan mengurangi kontaminasi dari polusi timbal yang berbahaya bagi pernafasan. Letak sekolah yang lebih tinggi dari jalan umum serta sistem irigasi yang lancar dan baik dapat menghindari sekolah dari banjir pada musim hujan. Tanaman dan sirkulasi udara yang ditata dengan baik sangat mendukung kenyamanan dalam proses belajar selama masa pendididkan serta dapat menjaga kesehatan dilingkingan sekolah.

\section{VISI DAN MISI SMK FARMASI CENDIKIA FARMA HUSADA}

* VISI

"mewujudkan sekolah yang unggul dalam mencetak asisten tenaga kefarmasian yang kompeten,disiplin,religius dan berdaya saing".

\section{* MISI}

1. Membangkitan kekuatan moral dan kesadaran tentang keberadaan Allah SWT Yang Masha Esa dan sadar bahwa setiap kehidupan akan dipertanggung jawabkan .

2. Menyelenggarakan proses pendidikan yang professional dan berkualitas agar peserta didik menjadi asisten tenaga kefarmasian yang berkemampuan akademik dan berdaya asing.

3. Melakukan pendidikan dan pengembangan karakter peserta didik agar memiliki kecerdasan emosional dan spiritual yang baik dalam menerapkan ilmu kefarmasian dimasyarakat.

4. Menggunakan teknologi informasi dalam penyelenggaraan pendidikan serta mengupayakan kemampuan penggunananya kepada peserta didik untuk meningkatkan daya asing diera digital.

\section{FRESTASI SMK FARMASI CENDIKIA FARMA HUSADA}

1. Juara $1 \mathrm{lks}$ tingkat kota bandar lampung

2. Juara 1 olimpiade sains terapan (ost) bidang biologi se provinsi lampung

3. Juara 1 lomba kompetisi siswa (lks) se provinsi lampung

4. Smk faramasi cendikia farma husada mendapat penghargaan dari mentri pendididkan nasional RI sebagai sekolah berintegritas tinggi tahun 2015

\section{SMK FARMASI CENDIKIA FARMA HUSADA BERGERAK DIBIDANG}

\section{"Yayasan Cendikia Farma Husada"}


DENAH LOKASI SMK FARMASI CENDIKIA FARMA HUSADA

\section{DENAH LOKASI}

SMK FARMASI CENDIKIA FARMA HUSADA

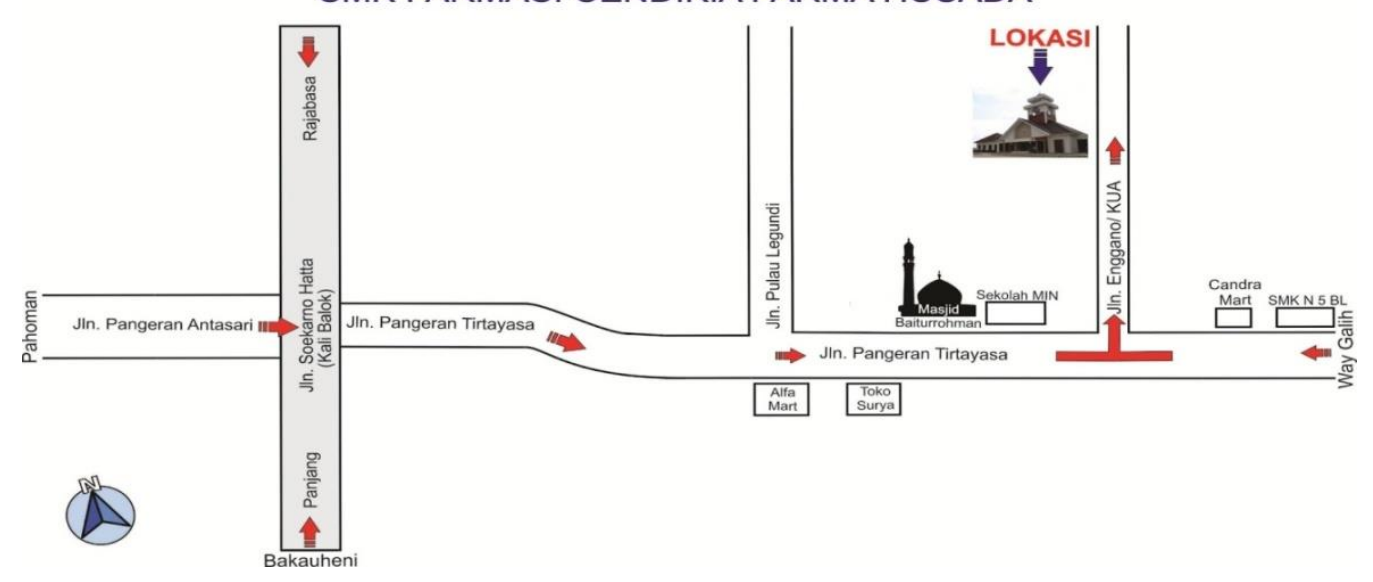




\section{BAB II}

\section{STRUKTUR SMK FARMASI CENDIKIA FARMA HUSADA}

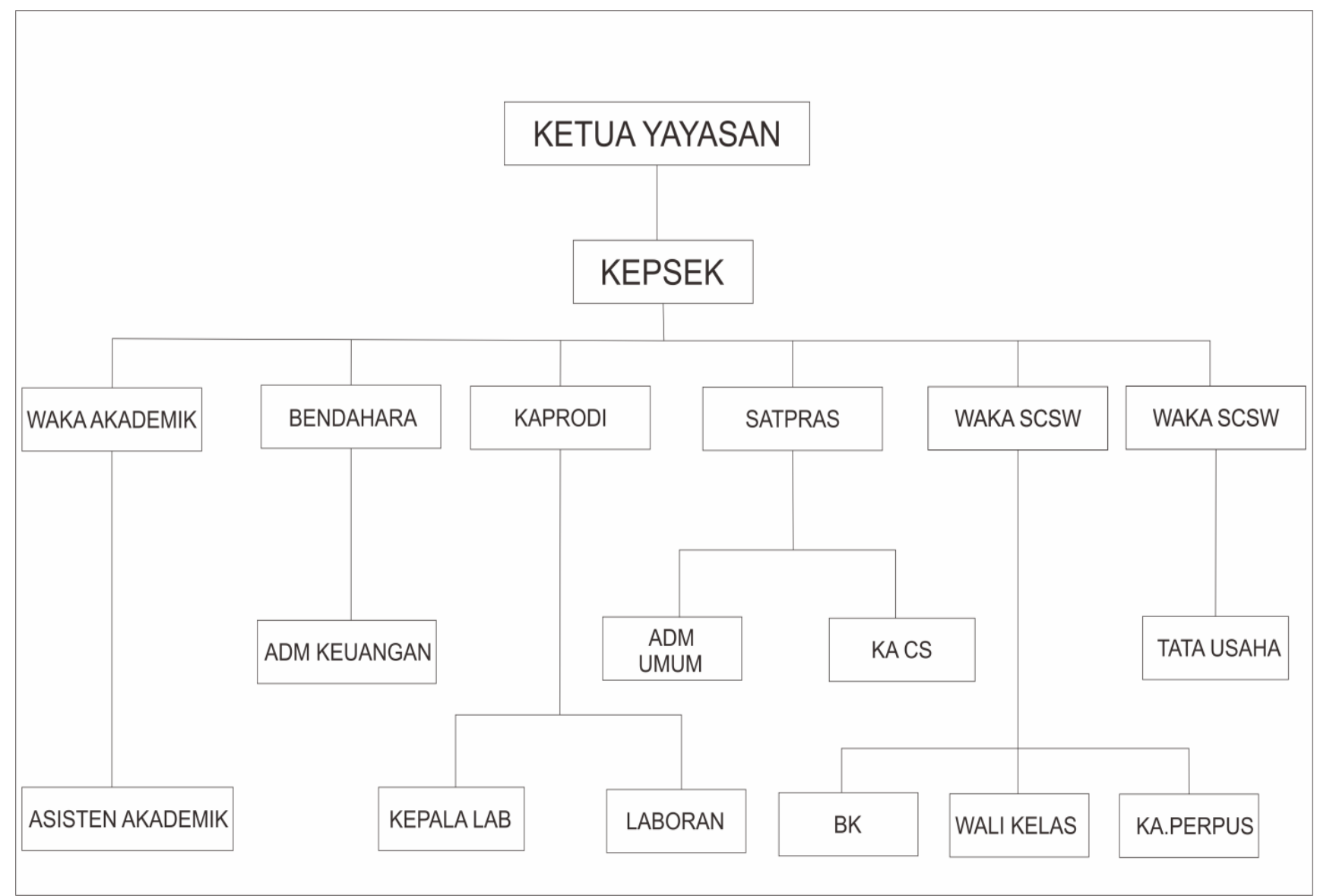

STRUKTUR DIVISI BENDAHARA

STRUKTUR DIVISI BENDAHARA

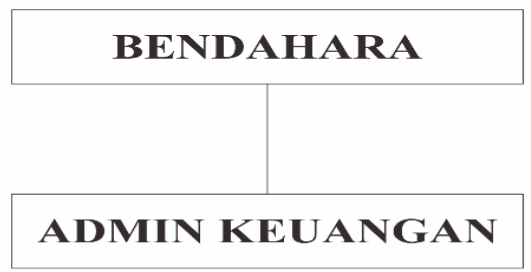




\section{BAB III}

\section{KUISIONER MANAGEMENT}

\begin{tabular}{|c|c|c|c|c|c|c|c|c|c|c|c|}
\hline \multirow[t]{2}{*}{ NO } & \multirow[t]{2}{*}{ Pernyataan } & \multicolumn{5}{|c|}{ Performance } & \multicolumn{5}{|c|}{ Expectasi } \\
\hline & & SB & B & C & TB & STB & SB & B & C & TB & STB \\
\hline \multicolumn{12}{|c|}{ DS6 MENGIDENTIFIKASI DAN MENGELOLA BIAYA } \\
\hline \multicolumn{12}{|c|}{ DS6.1 Ketentuan Jasa } \\
\hline 1. & $\begin{array}{l}\text { Bagaimana peringatan terhadap siswa } \\
\text { yang terlambat membayar SPP. }\end{array}$ & & & & & & & & & & \\
\hline 2. & $\begin{array}{l}\text { Identifikasi seluruh biaya dalam } \\
\text { sekolah yang transparan baik } \\
\text { terhadap siswa maupun orangtua. }\end{array}$ & & & & & & & & & & \\
\hline \multicolumn{12}{|c|}{ DS6.2 Akuntansi IT } \\
\hline 1. & $\begin{array}{l}\text { Terkomputerisasinya pembukuan } \\
\text { dalam sekolah SMK FARMASI } \\
\text { CENDIKIA FARMA HUSADA }\end{array}$ & & & & & & & & & & \\
\hline 2. & $\begin{array}{l}\text { Bagaimana cara menjaga data } \\
\text { keuangan agar tidak terjadi } \\
\text { kesalahan dalam perhitungan? }\end{array}$ & & & & & & & & & & \\
\hline \multicolumn{12}{|c|}{ DS6.3 Model dan Pemberian Tarif Biaya } \\
\hline 1. & $\begin{array}{l}\text { Bagaimana pembiayaan dalam } \\
\text { sekolah SMK FARMASI CENDIKIA } \\
\text { FARMA HUSADA? }\end{array}$ & & & & & & & & & & \\
\hline 2. & $\begin{array}{l}\text { Bagaimana metode pembayaran } \\
\text { dalam sekolah SMK FARMASI } \\
\text { CENDIKIA FARMA HUSADA. }\end{array}$ & & & & & & & & & & \\
\hline \multicolumn{12}{|c|}{ DS6.4 Pemeliharaan Model Biaya } \\
\hline 1. & $\begin{array}{l}\text { Bagaimana dalam menjaga dan } \\
\text { mengatasi agar tidak terjadi } \\
\text { keterlambatan saat pembayaran } \\
\text { uang sekolah? }\end{array}$ & & & & & & & & & & \\
\hline 2. & $\begin{array}{l}\text { Bagaimana kesesuaian uang SPP } \\
\text { dalam sekolah SMK FARMASI } \\
\text { CENDIKIA FARMA HUSADA? }\end{array}$ & & & & & & & & & & \\
\hline
\end{tabular}

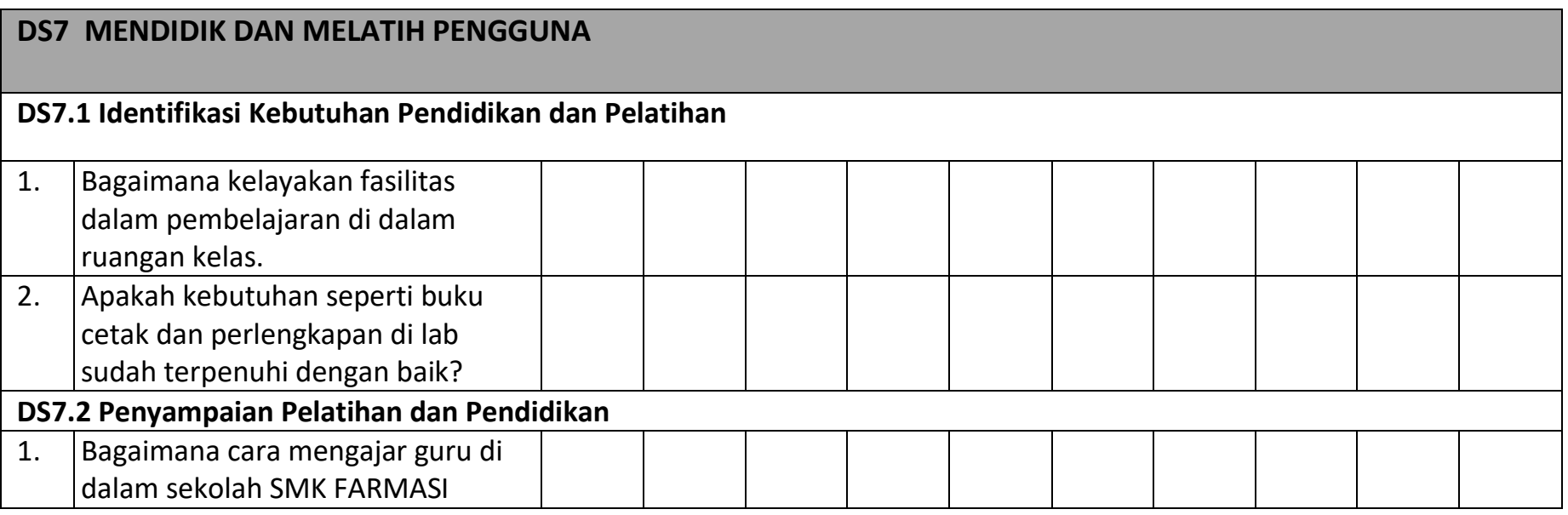




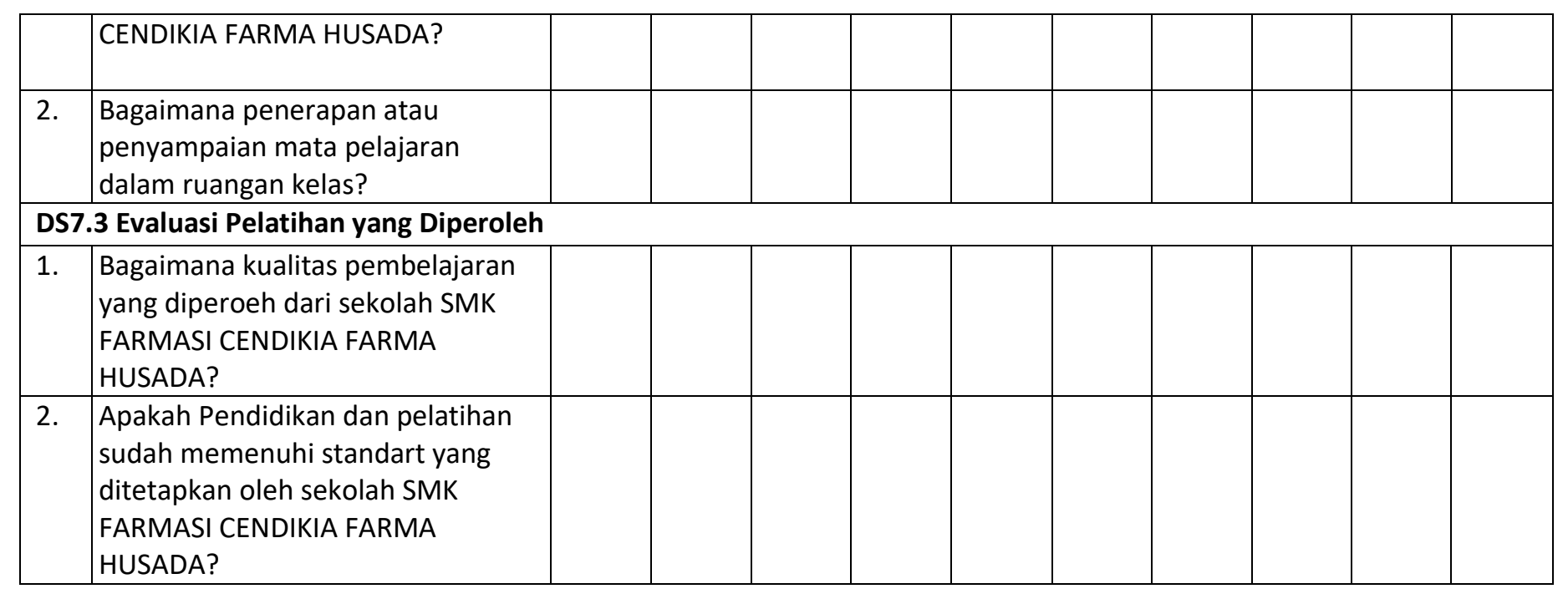

\section{KUISIONER USER}

\begin{tabular}{|l|c|c|c|c|c|c|c|c|c|c|c|}
\hline NO & Pernyataan & \multicolumn{9}{|c|}{ Performance } & \multicolumn{5}{|c|}{ Expectasi } \\
\cline { 3 - 10 } & & SB & B & C & TB & STB & SB & B & C & TB & STB \\
\hline
\end{tabular}

\section{DS6.1 Ketentuan Jasa}

$1 . \quad$ Bagaimana siswa menyikapi tentang keterlambatan dan denda pembayaran SPP?

2. $\quad$ Kenyaman saat pembayaran sesuai dengan prosedur yang ada.

\section{DS6.2 Akuntansi IT}

1. $\quad$ Tanggapan siswa apabila pembayaran dilakukan secara online.

2. Apakah data pembayaran sudah sesuai dengan dana yang ada?

\section{DS6.3 Model dan Pemberian Tarif Biaya}

\begin{tabular}{|l|l|l|l|l|l|l|l|l|l|}
\hline & & & & & & & & & \\
\hline & & & & & & & & & \\
\hline
\end{tabular}

1. $\quad$ Bagaimana siswa menyikapi tentang pembiayaan di sekolah SMK FARMASI CENDIKIA FARMA HUSADA?

2. $\quad$ Tanggapan siswa apabila pembayaran dilakukan antar bank. 
DS6.4 Pemeliharaan Model Biaya

\begin{tabular}{|l|l|l|l|l|l|l|l|l|l|}
\hline 1. & $\begin{array}{l}\text { Konsekuensi yang kalian dapat saat } \\
\text { telat melakukan pembayaran } \\
\text { sekolah. }\end{array}$ & & & & & & & & \\
\hline 2. & $\begin{array}{l}\text { Apakah siswa sudah merasakan } \\
\text { kesesuaian uang SPP di sekolah } \\
\text { SMK FARMASI CENDIKIA FARMA } \\
\text { HUSADA? }\end{array}$ & & & & & & & & \\
\hline
\end{tabular}

\section{DS7 MENDIDIK DAN MELATIH PENGGUNA}

\section{DS7.1 Identifikasi Kebutuhan Pendidikan dan Pelatihan}

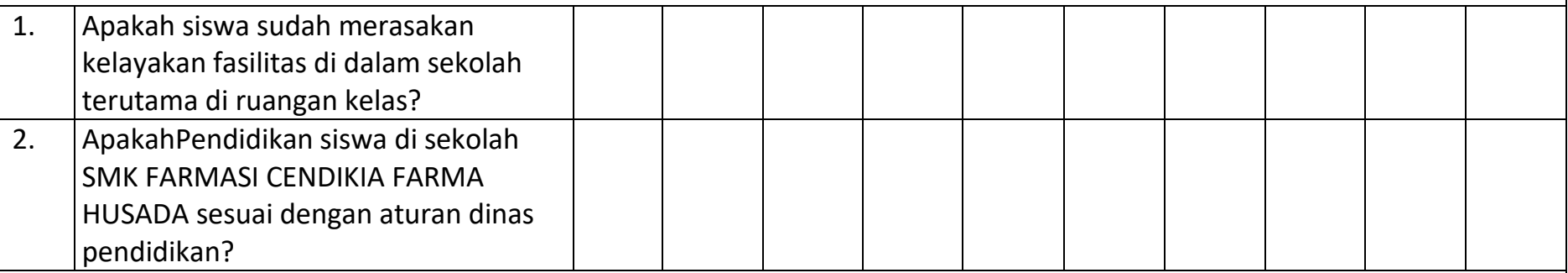

DS7.2 Penyampaian Pelatihan dan Pendidikan

\begin{tabular}{|l|l|l|l|l|l|l|l|l|l|}
\hline 1. & $\begin{array}{l}\text { Bagaimana penyampaian materi } \\
\text { pelajaran kepada siswa SMK FARMASI } \\
\text { CENDIKIA FARMA HUSADA? }\end{array}$ & & & & & & & & \\
\hline 2. & $\begin{array}{l}\text { Bagaimana siswa menanggapi mata } \\
\text { pelajaran ketika guru mengajar di } \\
\text { depan? }\end{array}$ & & & & & & & & \\
\hline DS7.3 Evaluasi Pelatihan yang Diperoleh & $\begin{array}{l}\text { Kualitas pendidikan yang didapat } \\
\text { disekolah. }\end{array}$ & & & & & & & & \\
\hline 2. & $\begin{array}{l}\text { Kualitas semua fasilitas yang } \\
\text { diperoleh disekoah. }\end{array}$ & & & & & & & & \\
\hline
\end{tabular}




\section{BAB IV}

\section{HASIL REKAP KUEISIONER USER}

\begin{tabular}{|c|c|c|c|c|c|c|c|c|}
\hline \multicolumn{9}{|c|}{ PERFORMANCE } \\
\hline & & No & SB & $\mathrm{B}$ & $\mathrm{C}$ & TB & STB & JLH \\
\hline 1 & DS6.1 & 1.1 & & 3 & 5 & & & 10 \\
\hline 2 & & 1.2 & & 7 & 1 & & & 10 \\
\hline 3 & DS6.2 & 2.1 & & 3 & & & & 10 \\
\hline 4 & & 2.2 & & 5 & 4 & & & 10 \\
\hline 5 & DS6.3 & 3.1 & & 3 & 7 & & & 10 \\
\hline 6 & & 3.2 & & 2 & & & & 10 \\
\hline 7 & DS6.4 & 4.1 & & 1 & 5 & & & 10 \\
\hline 8 & & 4.2 & & 3 & 3 & & & 10 \\
\hline 9 & DS7.1 & 5.1 & & 2 & 5 & & & 10 \\
\hline 10 & & 5.2 & & 5 & 1 & & & 10 \\
\hline 11 & DS7.2 & 6.1 & & 3 & 7 & & & 10 \\
\hline 12 & & 6.2 & & 3 & 6 & & & 10 \\
\hline 13 & DS7.3 & 1.1 & & 5 & & & & 10 \\
\hline 14 & & 1.2 & & 1 & 2 & & & 10 \\
\hline
\end{tabular}

EXPECTED
\begin{tabular}{|r|c|c|c|c|c|}
\hline \multicolumn{1}{|c|}{ SB } & B & C & TB & STB & JLH \\
\hline $\mathbf{5}$ & $\mathbf{5}$ & & & 10 \\
$\mathbf{9}$ & $\mathbf{1}$ & & & 10 \\
$\mathbf{1 0}$ & & & & 10 \\
$\mathbf{6}$ & $\mathbf{4}$ & & 10 \\
$\mathbf{3}$ & $\mathbf{7}$ & & 10 \\
$\mathbf{1 0}$ & & & 10 \\
$\mathbf{8}$ & $\mathbf{2}$ & & 10 \\
$\mathbf{1 0}$ & & & 10 \\
$\mathbf{5}$ & $\mathbf{5}$ & & 10 \\
$\mathbf{9}$ & $\mathbf{1}$ & & 10 \\
$\mathbf{2}$ & $\mathbf{8}$ & & 10 \\
$\mathbf{3}$ & $\mathbf{7}$ & & 10 \\
$\mathbf{9}$ & $\mathbf{1}$ & & 10 \\
$\mathbf{8}$ & $\mathbf{2}$ & & 10 \\
\hline
\end{tabular}

\begin{tabular}{|c|c|c|c|c|}
\hline \multicolumn{2}{|c|}{ PERFORMANCE } & \multicolumn{2}{|c|}{ EXPECTED } & \multirow{3}{*}{ Gap } \\
\hline \multicolumn{4}{|c|}{ MATURITY } & \\
\hline ACTIVITY & PROSES & ACTIVITY & PROSES & \\
\hline 2.47 & \multirow{2}{*}{2.60} & 3.00 & \multirow{2}{*}{3.13} & \multirow[b]{2}{*}{0.53} \\
\hline 2.73 & & 3.27 & & \\
\hline 3.13 & \multirow{2}{*}{2.80} & 3.33 & \multirow{2}{*}{3.20} & \\
\hline 2.47 & & 3.07 & & 0.40 \\
\hline
\end{tabular}




\begin{tabular}{|c|c|c|c|c|}
\hline 2.20 & \multirow{2}{*}{2.70} & 2.87 & \multirow{2}{*}{3.10} & \multirow[b]{2}{*}{0.40} \\
\hline 3.20 & & 3.33 & & \\
\hline 2.60 & \multirow{2}{*}{2.67} & 3.20 & \multirow{2}{*}{3.27} & \\
\hline 2.73 & & 3.33 & & 0.60 \\
\hline 2.53 & \multirow{2}{*}{2.70} & 3.00 & \multirow{2}{*}{3.13} & \\
\hline 2.87 & & 3.27 & & 0.43 \\
\hline 2.20 & \multirow{2}{*}{2.27} & 2.80 & \multirow{2}{*}{2.83} & \\
\hline 2.33 & & 2.87 & & 0.57 \\
\hline 3.00 & \multirow{2}{*}{3.00} & 3.27 & \multirow{2}{*}{3.23} & \\
\hline 3.00 & & 3.20 & & 0.23 \\
\hline
\end{tabular}

\section{REKAP HASIL KUESIONER MANAGEMENT}

\begin{tabular}{|rl|c|c|c|c|c|c|c}
\multicolumn{7}{c}{ PERFORMANCE } \\
\cline { 4 - 8 } 1 & DS6.1 & No & SB & B & C & TB & STB & JLH \\
2 & & 1.1 & & $\mathbf{2}$ & $\mathbf{3}$ & & 5 \\
3 & DS6.2 & 2.1 & $\mathbf{2}$ & $\mathbf{3}$ & & & 5 \\
4 & & $\mathbf{1}$ & $\mathbf{3}$ & $\mathbf{1}$ & & 5 \\
5 & DS6.3 & 2.2 & $\mathbf{1}$ & $\mathbf{4}$ & & & 5 \\
6 & & 3.1 & & $\mathbf{2}$ & $\mathbf{3}$ & & 5 \\
7 & DS6.4 & 4.1 & $\mathbf{1}$ & $\mathbf{2}$ & $\mathbf{2}$ & & 5 \\
8 & & $\mathbf{1}$ & $\mathbf{2}$ & $\mathbf{2}$ & & 5 \\
9 & DS7.1 & 4.2 & 5.1 & $\mathbf{3}$ & $\mathbf{2}$ & & & 5 \\
10 & & $\mathbf{2}$ & $\mathbf{3}$ & & & 5 \\
11 & DS7.2 & 5.2 & 6.1 & & $\mathbf{1}$ & $\mathbf{4}$ & & 5 \\
12 & & 6.2 & $\mathbf{2}$ & $\mathbf{2}$ & $\mathbf{1}$ & & 5 \\
13 & DS7.3 & 1.1 & $\mathbf{2}$ & $\mathbf{3}$ & & & 5 \\
14 & & 1.2 & & $\mathbf{4}$ & $\mathbf{1}$ & & 5 \\
\hline
\end{tabular}

\begin{tabular}{|c|c|c|c|c|c|}
\hline \multicolumn{6}{|c|}{ EXPECTED } \\
\hline SB & B & C & TB & STB & JLH \\
\hline 2 & & & & & 5 \\
\hline 4 & & & & & 5 \\
\hline 4 & & & & & 5 \\
\hline 4 & & & & & 5 \\
\hline 1 & & & & & 5 \\
\hline 2 & & & & & 5 \\
\hline 2 & & & & & 5 \\
\hline 5 & & & & & 5 \\
\hline 5 & & & & & 5 \\
\hline 1 & & & & & 5 \\
\hline 4 & & & & & 5 \\
\hline 5 & & & & & 5 \\
\hline 5 & & & & & 5 \\
\hline 4 & & & & & 5 \\
\hline
\end{tabular}




\begin{tabular}{|c|c|c|c|c|}
\hline \multicolumn{2}{|c|}{ PERFORMANCE } & \multicolumn{2}{|c|}{ EXPECTED } & \multirow{3}{*}{ Gap } \\
\hline \multicolumn{4}{|c|}{ MATURITY } & \\
\hline ACTIVITY & PROSES & ACTIVITY & PROSES & \\
\hline 3.40 & \multirow{2}{*}{3.90} & 4.40 & \multirow{2}{*}{4.60} & \multirow[b]{2}{*}{0.70} \\
\hline 4.40 & & 4.80 & & \\
\hline 4.00 & \multirow{2}{*}{4.10} & 4.80 & \multirow{2}{*}{4.80} & \multirow[b]{2}{*}{0.70} \\
\hline 4.20 & & 4.80 & & \\
\hline 3.40 & \multirow{2}{*}{3.60} & 4.20 & \multirow{2}{*}{4.30} & \multirow[b]{2}{*}{0.70} \\
\hline 3.80 & & 4.40 & & \\
\hline 3.80 & \multirow{2}{*}{4.20} & 4.40 & \multirow{2}{*}{4.70} & \multirow[b]{2}{*}{0.50} \\
\hline 4.60 & & 5.00 & & \\
\hline 4.40 & \multirow{2}{*}{3.80} & 5.00 & \multirow{2}{*}{4.60} & \multirow[b]{2}{*}{0.80} \\
\hline 3.20 & & 4.20 & & \\
\hline 4.20 & \multirow{2}{*}{4.20} & 4.80 & \multirow{2}{*}{4.90} & \multirow[b]{2}{*}{0.70} \\
\hline 4.20 & & 5.00 & & \\
\hline 4.40 & \multirow{2}{*}{4.10} & 5.00 & \multirow{2}{*}{4.90} & \multirow{2}{*}{0.80} \\
\hline 3.80 & & 4.80 & & \\
\hline
\end{tabular}

\section{Perhitungan User \& Management}

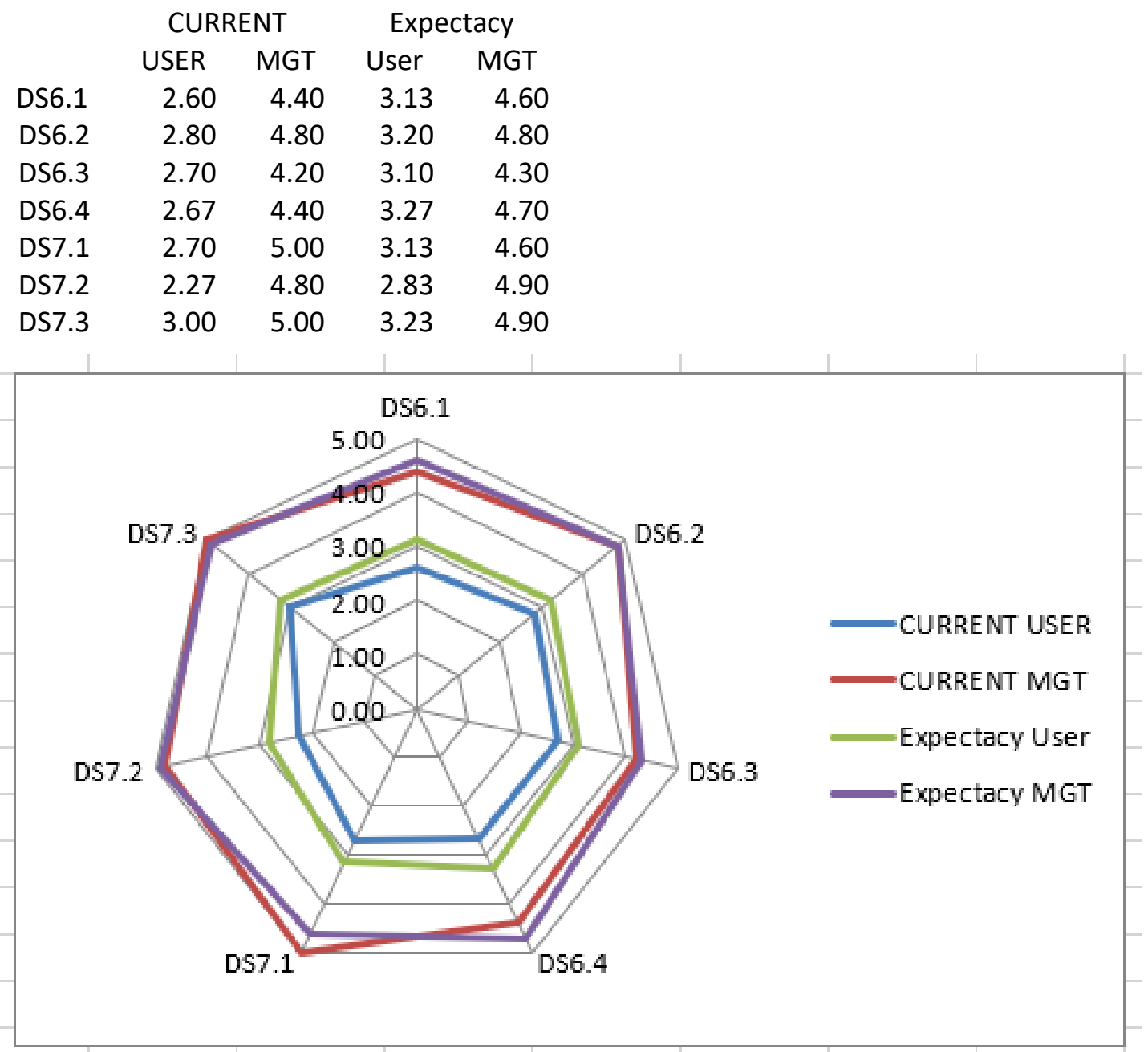




\section{Perhitungan USER}

$\begin{array}{cr}\begin{array}{c}\text { CURRENT } \\ \text { USER }\end{array} & \begin{array}{c}\text { Expectacy } \\ \text { User }\end{array} \\ 2.60 & 3.00 \\ 2.80 & 3.33 \\ 2.70 & 2.87 \\ 2.67 & 3.20 \\ 2.70 & 3.00 \\ 2.27 & 2.80 \\ 3.00 & 3.27\end{array}$

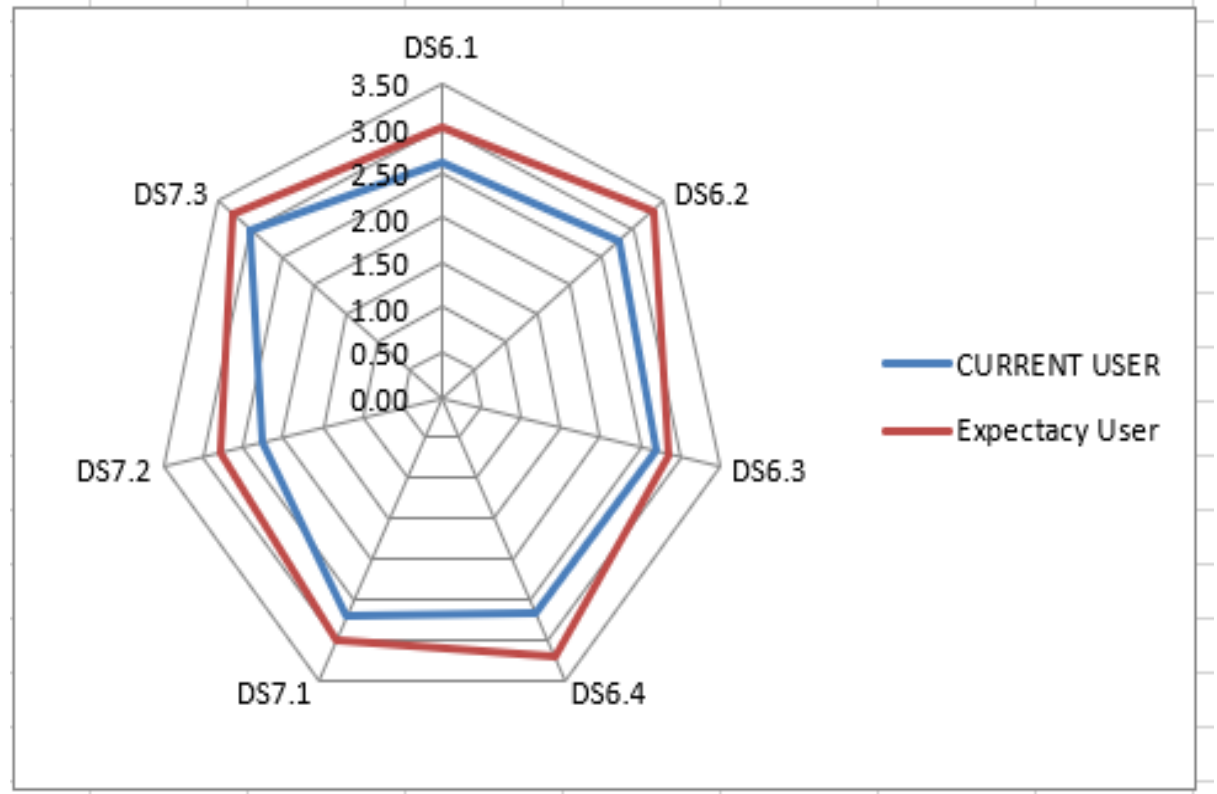

\section{Perhitungan Management}

\begin{tabular}{|c|c|c|}
\hline & $\begin{array}{c}\text { CURRENT } \\
\text { MGT }\end{array}$ & $\begin{array}{c}\text { Expectacy } \\
\text { MGT }\end{array}$ \\
\hline DS6.1 & 4.40 & 4.60 \\
\hline DS6.2 & 4.80 & 4.80 \\
\hline DS6.3 & 4.20 & 4.30 \\
\hline DS6.4 & 4.40 & 4.70 \\
\hline DS7.1 & 5.00 & 4.60 \\
\hline DS7.2 & 4.80 & 4.90 \\
\hline DS7.3 & 5.00 & 4.90 \\
\hline
\end{tabular}

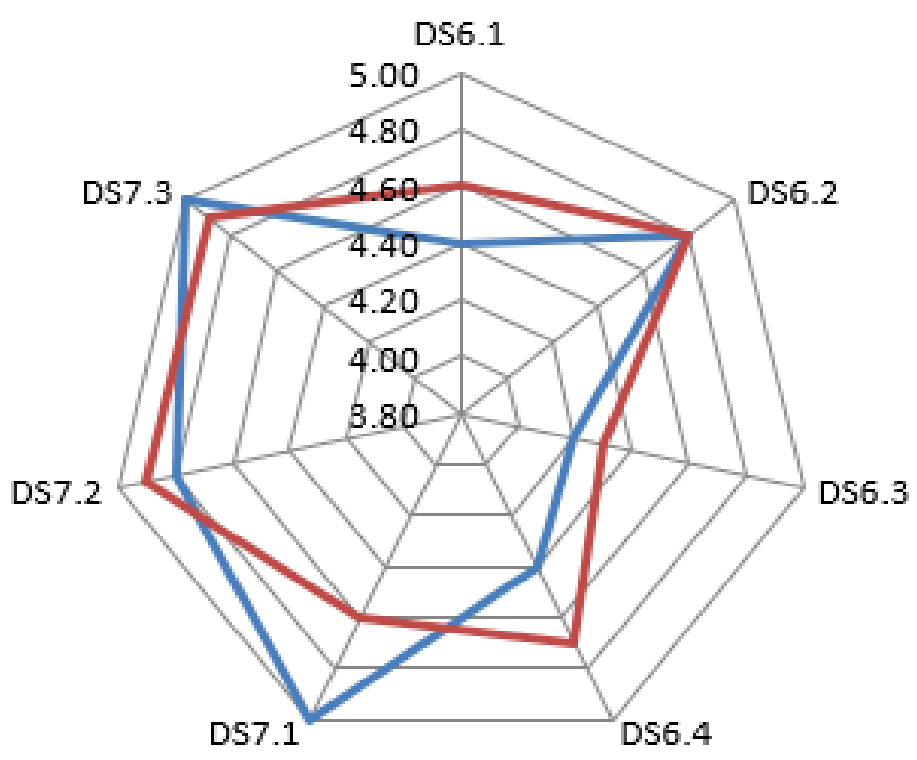

C CURRENT MGT

Expectacy MGT 


\section{BAB V}

\section{Saran}

- Lebih memudahkan siswa pada saat pembayaran

- Lebih transparan kepada siswa maupun orang tua tentang keuangan yang ada di dalam sekolah

○ Lebih mengutamakan apa yang menjadi kebutuhan siswa pada saat pembayaran uang spp

\section{Kesimpulan}

Dari hasil audit yang saya lakukan di SMK FARMASI CENDIKIA FARMA HUSADA sudah bias dikatakan cukup baik dalam segi keuangan dan bendahara maupun sarana dan prasarana yang berada di dalam sekolah, hanya saja mungkin harus diperbaiki lagi dalam penyampaian informasi kepada pendatang atau tamu yang datang berkunjung kesekolahan tersebut. 


\section{LAMPIRAN}
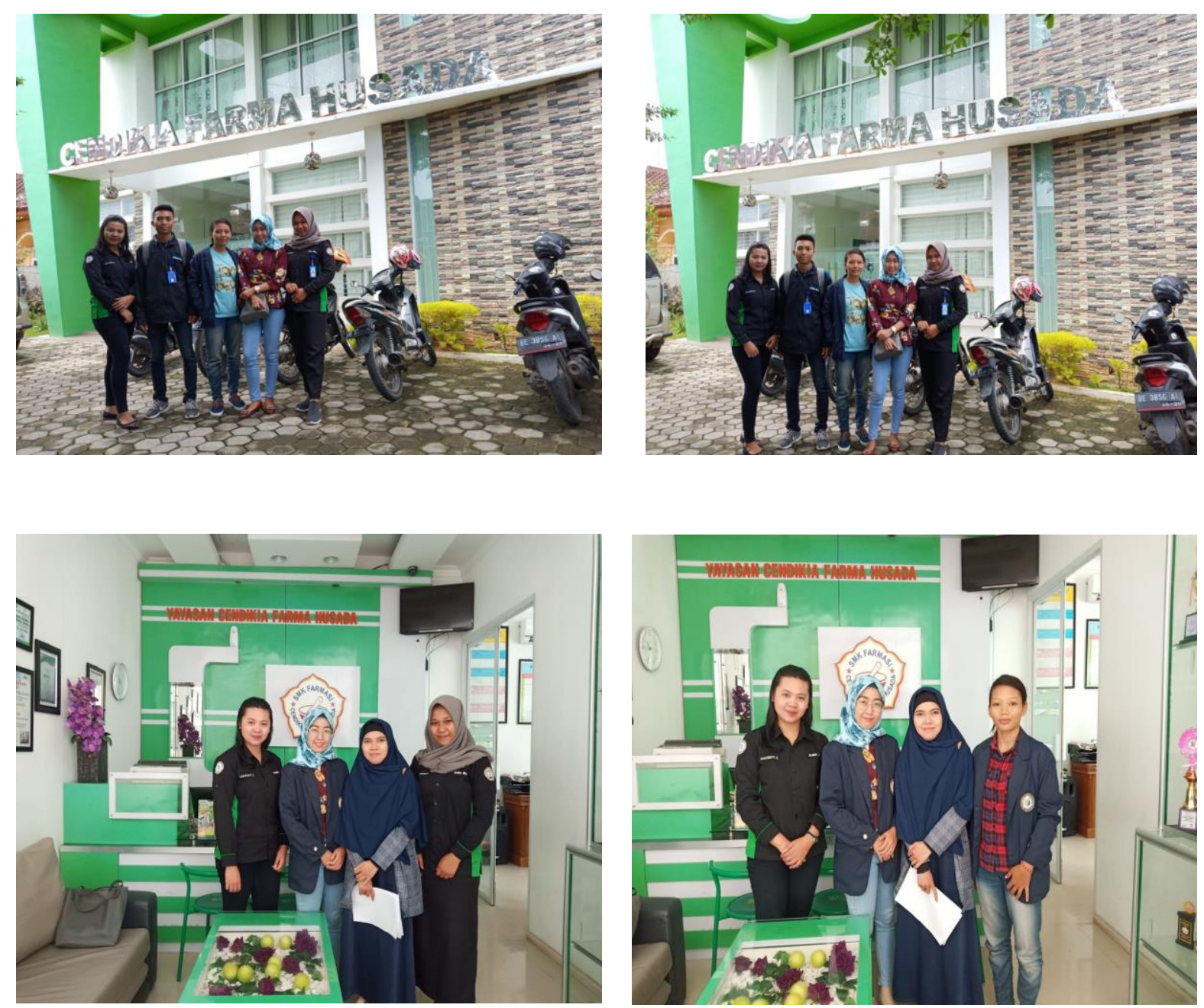

\section{MOTTO:}

"Jadilah orang yang tidak pernah takut untuk mengambil suatu keputusan yang besar,karena dengan keputusan yang besar itulah kita akan lebih percaya dengan diri sendiri"

"Tidak ada yang tidak mungkin selama kita yakin,jangan pernah ragu dengan kemampuan yang ada,tetaplah berusaha dan berdoa" 